\title{
Effect of a Deep Cryogenic Treatment on Wear and Microstructure of a 6101 Aluminum Alloy
}

\author{
Volker Franco Steier, ${ }^{1}$ Edgar Sobral Ashiuchi, ${ }^{2}$ Lutz Reißig, ${ }^{3}$ and José Alexander Araújo ${ }^{2}$ \\ ${ }^{1}$ Department of Automotive Engineering, University of Brasilia, 72444-240 Brasilia, DF, Brazil \\ ${ }^{2}$ Department of Mechanical Engineering, University of Brasilia, 70910-900 Brasilia, DF, Brazil \\ ${ }^{3}$ Fraunhofer Institute for Mechanics of Materials IWM, Woehlerstrasse 11, 79108 Freiburg, Germany
}

Correspondence should be addressed to Volker Franco Steier; vfs@unb.br

Received 14 October 2015; Accepted 5 May 2016

Academic Editor: Francesco Delogu

Copyright (C) 2016 Volker Franco Steier et al. This is an open access article distributed under the Creative Commons Attribution License, which permits unrestricted use, distribution, and reproduction in any medium, provided the original work is properly cited.

\begin{abstract}
The aim of this work is to evaluate the effect of a deep cryogenic treatment (DCT) on the wear behavior and on the microstructure of an aluminum alloy. In order to compare the level of improvement on the wear resistance provided by the DCT with a more traditional technique, a test matrix which included DCT, CrN coated specimens, and combinations of both modification methods was conducted. The wear behavior was investigated using microabrasive wear tests. The cryogenic treated specimens proved to have similar low wear rates as the specimens coated with $\mathrm{CrN}$. The most distinct improvement was reached with a combination of both techniques. In the case of the DCT, the performed microstructural analysis identified the generation of additional GP-zones as the reason for the improved wear resistance.
\end{abstract}

\section{Introduction}

Especially in the automotive sector, the use of aluminum is steadily increasing in order to reduce the weight of cars, which improves the efficiency and reduces the emission of $\mathrm{CO}_{2}$. The drawbacks of aluminum are its low yield strength and the low wear resistance (wear resistance is 1 /wear rate). One possibility to enhance the mechanical properties of aluminum is to add alloying elements like silicon, manganese, or magnesium [1-3]. However, the wear resistance of aluminum alloys is still insufficient for many applications.

One possibility to improve the wear resistance of aluminum alloys is to apply deep cryogenic treatments (DCTs). One of the advantages of DCTs is that the microstructural changes occur in the entire bulk material and not just on the surface (as it is the case for coatings) [4]. DCTs have been widely used in many industries such as aerospace and automotive, electronic, and mechanical engineering to improve the wear resistance and the dimensional stability of steel components [5]. However, no industrial application of DCTs for aluminum components has so far been established and there are just few published works on the effect of DCTs on aluminum and aluminum alloys.
A first investigation regarding the effect of DCTs on residual stresses of an aerospace aluminum alloy was carried out in 2000 [6]. In the following years, several researchers applied DCTs on different aluminum alloys [7-10]. In most cases, it was reported an improvement of the mechanical properties after the application of DCTs. However, these studies did not try to explain the possible causes associated with such behavior. More recent work has suggested that the formation of hard second phases (like $\mathrm{Mg}_{2} \mathrm{Si}$ or $\mathrm{Al}_{x} \mathrm{Fe}_{x} \mathrm{Si}_{x}$ ) [11-13], grain size effects [8], and the generation of dislocations [14] could be related to the reported improvements, but more firm conclusions were not provided. In this setting, the aim of this work is to comprehensively investigate the effect of DCTs on the wear resistance and on the microstructure of an aluminum alloy.

\section{Methods}

To compare the impact of DCTs on the wear behavior, five different groups of specimens were tested. First, a group of unmodified specimens, which act as a reference material, was tested. The second group of specimens was modified 
with a DCT. The third batch consisted of specimens that were coated with a chromium nitride $(\mathrm{CrN})$ layer. This batch was added to the test matrix to compare the effect of the DCT with a more traditional technique known to improve the wear resistance [15-17]. Zhou et al. showed that $\mathrm{CrN}$ coatings exhibit an excellent sliding wear resistance, when deposited on aluminum alloys $[18,19]$. For this reason, $\mathrm{CrN}$ was chosen as surface coating for this work. The fourth and fifth batches were modified with a combination of DCT and a $\mathrm{CrN}$ coating. The difference between both batches was the order of application of the modification methods.

All five batches were tested in comparative microabrasive wear tests, and, to identify the effect of DCTs on the microstructure of the aluminum alloy, a comprehensive series of analysis was carried out. It included classical metallographic methods supported by light microscopy, Scanning Electron Microscopy (SEM), Transmission Electron Microscopy (TEM), hardness tests, energy-dispersive spectroscopy (EDS), X-Ray Diffraction (XRD) analysis, and differential scanning calorimetry (DSC). Details on the test procedures, on the application of these analyses techniques and on the material/specimens considered, are provided next.

2.1. Material. The raw material used for the tests was an aluminum alloy 6101-T4. To operate as reference material, the alloy was tested as received (further named as AR). More precisely, the state of the alloy should be defined as naturally aged, since the aluminum specimens were not tested just after production. The nominal chemical composition of this material is given in Table 1 .

2.2. Modification Methods. The DCT was applied by the company Kyros Tecnologia. The process starts at room temperature and goes down to $-190^{\circ} \mathrm{C}$ within a period of $12 \mathrm{~h}$. The temperature of $-190^{\circ} \mathrm{C}$ is kept constant for further $12 \mathrm{~h}$. After this dwell time, the temperature is increased to room temperature within $12 \mathrm{~h}$. Before the liquid nitrogen is injected in the chamber, it was evaporated to enable a controlled cooling and to prevent a severe gradient of temperature between the surface and the core of the specimens. The deep cryogenically treated specimens are henceforth named CTed.

Physical vapor deposition was used to apply the CrN coating by an external contract. As target, a $99.9 \%$ pure chromium was used. The deposition was carried out in a $\mathrm{N}_{2}$ atmosphere. Besides a thoroughly cleaning of the specimens with alcohol in an ultrasonic bath, no further treatment was applied before the coating process. Due to the microstructural changes, which can be generated in aluminum alloys, a low temperature during the coating process is important. CrN was selected for the tests as it could be deposited at comparable low temperatures. These specimens are henceforth named CrNC.

To investigate if a combination of both modification methods could lead to a superposition of effects, two additional test series were carried out. One was a series where the CTed specimens were subsequently coated (combination of DCT and coating-1, Comb-1) and the other consisted of coated specimens that were later submitted to DCT (combination of coating and DCT-2, Comb-2). To improve
TABLE 1: Nominal chemical composition of the aluminum alloy 6101T4.

\begin{tabular}{lcccccccc}
\hline Elements & $\mathrm{Al}$ & $\mathrm{Si}$ & $\mathrm{Mg}$ & $\mathrm{Fe}$ & $\mathrm{Cu}$ & $\mathrm{Mn}$ & $\mathrm{Cr}$ & $\mathrm{Zn}$ \\
\hline Percentage & 98.8 & $0.3-0.7$ & $0.3-0.8$ & 0.5 & 0.1 & 0.03 & 0.03 & 0.01 \\
\hline
\end{tabular}

TABLE 2: Specimens abbreviations.

\begin{tabular}{lc}
\hline Treatment applied to the specimens & Abbreviation \\
\hline As received & $\mathrm{AR}$ \\
\hline Deep cryogenic treatment & CTed \\
\hline Coated with a CrN layer & CrNC \\
\hline $\begin{array}{l}\text { Cryogenically treated and afterwards } \\
\text { coated with CrN }\end{array}$ & Comb-1 \\
\hline $\begin{array}{l}\text { First coated with CrN and afterwards } \\
\text { cryogenically treated }\end{array}$ & Comb-2
\end{tabular}

the readability of the paper, a list of abbreviations for the specimens in reported in Table 2.

To guarantee equal surface conditions, all specimens were polished under equal conditions (before the coating process and the DCT). The polishing was carried out with abrasive paper (grit 1200), until the surface was optically equal.

2.3. X-Ray Diffraction. X-Ray Diffraction (XRD) spectroscopy was used to investigate the effect of the DCT on the aluminum alloy. For the measurements, a high resolution Rigaku Ultima IV, with a $\mathrm{Cu} \mathrm{K} \alpha$ source and a wavelength of $1.54 \mathrm{~A}$ was used. The scan was performed with a step size of $0.5^{\circ} / \mathrm{min}$ from an angel of $0^{\circ}$ to $120^{\circ}$. The voltage and current settings were $35 \mathrm{kV}$ and $15 \mathrm{~mA}$, respectively.

2.4. Hardness Measurements. To examine the effect of the cryogenic treatment on the hardness, Vickers indentations were carried out (Zwick ZHU 250). Ten indentations were performed with HV1 $(10 \mathrm{~N})$. The force was applied for $10 \mathrm{~s}$ and measures were taken with an optical microscope.

For coated specimens, the coating was removed to conduct hardness tests. This was done by polishing the specimens with an abrasive aluminum suspension (mean particle size $0.5 \mu \mathrm{m}$ ). The polishing process was executed by hand with very low forces to avoid the creation of residual stresses. The process was frequently interrupted and visually controlled to remove only the surface coating and maintain the near surface substrate material.

To avoid that microstructural differences between the specimens affect the hardness analysis of the CTed and the AR specimens, the hardness measurements were carried out on the same sample. This means that the hardness was first examined in the AR state. The same sample was then treated cryogenically. Subsequently, the hardness was measured again close to the previously performed indentations.

2.5. Microstructure Analysis. To investigate the microstructure of the specimens before and after the DCT, polished and etched surfaces were photographed. The polishing process was executed using different diamond suspensions down to a grain size of $1 \mu \mathrm{m}$. For the final polish, an oxide polishing 
suspension was used (Struers). The etching was carried out using a Barker etchant. The microscopic images were taken with an optical microscope using polarized light.

The TEM was performed in the material engineering department in the Pontifical Catholic University of Rio de Janeiro (JEOL JEM 2100F). The acceleration voltage used was $200 \mathrm{kV}$. The preparation of the specimens was carried out in two steps. First, the specimens size was reduced to a thickness of $100 \mu \mathrm{m}$. Subsequently, a common electropolishing process was applied to reduce the specimens height to the needed thickness. The electrolyte consisted of nitric acid and methanol in a mass fraction of $30 \%$ and $75 \%$, respectively. The used voltage was $20 \mathrm{~V}$ at a temperature of $20^{\circ} \mathrm{C}$.

2.6. Differential Scanning Calorimetry (DSC). Due to the difficulties to observe ultrafine precipitates like GuinierPreston-zones (GP-zones) by using SEM or TEM, DSC was used to analyze the microstructural differences generated by the DCT (Perkin Elmer, DSC 8500). The measurement was executed with a constant Argon purge, to avoid oxidation reactions. After an initial dwell time $\left(2 \mathrm{~min}, 20^{\circ} \mathrm{C}\right)$ to homogenize the samples temperature, a heating rate of $20 \mathrm{~K} / \mathrm{min}$ was considered. A further 2 min dwell time was applied at the final temperature of $330^{\circ} \mathrm{C}$. As usual for DSC measurements, an empty specimen container, made of aluminum, was used as a reference. The test was carried out with two samples. Both samples (AR and CTed) had the same mass of $28.5 \mathrm{mg}$. To better visualize the differences between the CTed and the AR aluminum alloy, the DSC signals were subtracted one from the other.

2.7. Abrasive Wear Tests. The abrasive wear tests were performed with a Calowear testing machine (CSM Instruments SA) (Figure 1). The samples were mounted in an angle of $80^{\circ}$ versus the horizontal. As rotating sphere, a steel ball (Inox 420) with a diameter of $20 \mathrm{~mm}$ was used. The ball was preroughened by preliminary wear tests to enable a good entrainment of the slurry in the contact zone [20]. The rotation direction of the steel ball was adjusted so that the abrasive slurry was directly fed in the abrasive contact. The tests were executed with a ball speed of $0.1 \mathrm{~m} / \mathrm{s}$. The contact force between the contact parts depends on the weight, the distance, and the angle between the ball and the specimens. Those parameters were kept constant for all tests. In order to archive three-body wear, the contact force was kept at a comparable low level of $0.05 \mathrm{~N}$ for all tests $[20,21]$. As abrasive medium, a mixture of deionized water and $\mathrm{Al}_{2} \mathrm{O}_{3}$ was used (weight\% 31:69, resp., $\mathrm{Al}_{2} \mathrm{O}_{3}: \mathrm{H}_{2} \mathrm{O}$ ). The specification of the ceramic powder given by the manufacturer is D20-0.35 $\mu \mathrm{m}$, D50-0.6 $\mu \mathrm{m}$, and D90-1.4 $\mu \mathrm{m}$ (CR6, Baikowski).

To investigate the volume loss as a function of the sliding distance, six craters were generated on each sample. After a predefined sliding distance was reached, the tests were interrupted. The defined sliding distances were 22, 32, 49, 65,81 , and $105 \mathrm{~m}$. To avoid interaction between the single spheres, a distance of at least $3 \mathrm{~mm}$ was maintained.

The diameter of the crater was measured with an optical microscope using a circular caliber whose size was adapted

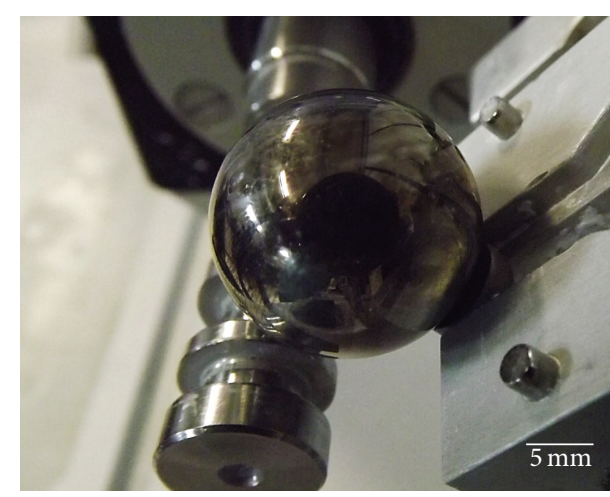

FIgURE 1: Microabrasive wear test.

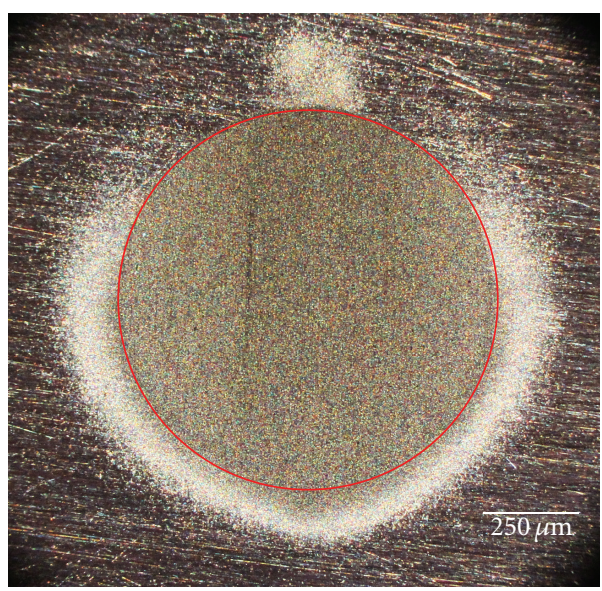

FIGURE 2: Crater on an AR sample with scuffed area around the crater.

until the distinct edges of the crater were congruent (Figure 2, red line).

Deviating from the common measurement method where two $90^{\circ}$ tilled measurements are used, this method avoids the common problem that one of the distance measurements needs to be done in the scuffed edges, where a clear definition of the edge is impossible.

In this research, no separate analysis of the wear coefficient of the substrate $\left(\kappa_{s}\right)$ and the wear coefficient of the coating $\left(\kappa_{c}\right)$ was carried out, as only the collective wear coefficient was used to evaluate the effect on the wear resistance. This means that the results of the coated specimens always show a mean wear rate consisting of $\kappa_{s}$ and $\kappa_{c}$ (Figures 5,6 , and 7).

\section{Calculation}

The modified Archard equation was used [22] to calculate the wear rate of all uncoated specimens. According to this equation, the wear rate $\kappa$ can be calculated by dividing the removed volume $V$ by the sliding distance $S$ and the applied normal load $N$ :

$$
\kappa=\frac{V}{S \cdot N}
$$


The total wear volume, $V$, can be calculated using the diameter of the generated crater $b$ and the radius $R$ of the steel ball [22]:

$$
V \approx \frac{\pi \cdot b^{4}}{64 \cdot R} \quad \text { for } b \ll R
$$

\section{Results}

4.1. Wear Tests. As described in the methodology, the thickness of the coating was determined using a SEM. One representative image of a coated sample is shown in Figure 3. The coated surface can be clearly identified by the bright layer.

A mean coating thickness of $660 \mathrm{~nm}$ was measured.

To identify the wear mechanisms generated by the microabrasive wear test, a surface investigation of the generated craters was carried out. In Figure 4, two images of the crater surface are shown to illustrate the arising wear mechanism. This wear mechanism was observed on the surfaces of all tested specimens.

Figure 4(a) shows one crater generated with many continuous vertically oriented grooves. The grooves were generated by the microabrasive wear tests due to microcutting [23]. Their regular and continuous appearance indicates a twobody wear behavior. In this case, the abrasive wear particles are attached to the rotating ball and therefore generate straight grooves. The measured width of the grooves was between $0.6 \mu \mathrm{m}$ and $1.5 \mu \mathrm{m}$. This fits well to the particle size of the abrasive slurry (see Section 2.7).

The SEM image in Figure 4(b) shows two types of grooves. First, the continuous groves which are related to particles attached to the rotating ball. Second, grooves show the repetitive occurrence of indentations. An explanation for the appearance of such indentations can be the combination of two- and three-body wear mechanisms. The cyclic indentations in the grooves can be generated by big, rotating particles. The distance between the indentations is approximately $1.9 \mu \mathrm{m}$, which is in accordance with the specification of the abrasive powder. It is therefore assumed that the cyclic indentations are generated by particles which have been pushed into the substrate. After the particles penetrated in the substrate, the ball rotation provoked anew displacement of the particle. The cyclic indentations indicate that such particles are not moved out of the contact but just pushed only one revolution further, before a new penetration into the substrate occurs. Since the particles are not permanently attached to the rotating ball, the wear mechanism for the scratches with cyclic indentations can be categorized as a sort of three-body wear.

Both sorts of scratches were found in all substrate materials, for which reason a mixed wear regime can be assumed in all tested specimens.

The results of the wear tests are shown in Figures 5-7. Each point shown in Figures 5 and 6 represents the average of three measurements carried out on three different equally treated specimens after a prescribed sliding distance. The error bars illustrate the deviation of the single measurement points. Figure 5 depicts the wear volume versus the sliding distance, $S$, multiplied by the contact force, $N$. Since $N$ was

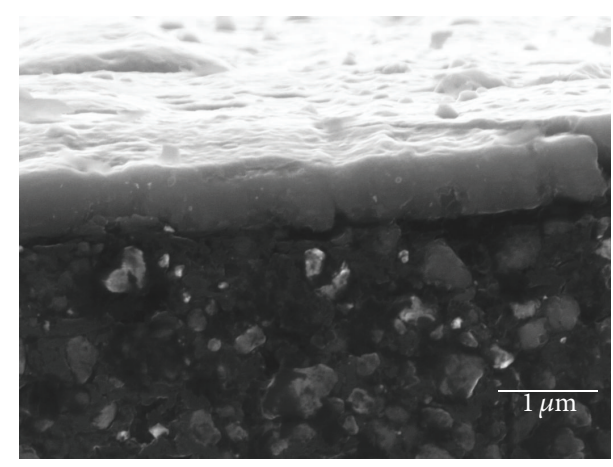

FIgURE 3: CrN surface coating.

kept constant, the diagram can also be understood as a plot of the removed volume against the sliding distance. From this figure, one can notice that the specimens tested under AR conditions show the highest amount of removed volume, while the Comb-2 specimens show the lowest one. The curves for the CrNC, the Comb-1, and the CTed specimens are similar.

Figure 6 shows the calculated wear rate of the same tests. One can notice that the AR specimens presented a relatively high wear rate while all modified specimens showed clearly lower wear rates. Focusing on the curve progression of the AR specimens, the wear rates decrease drastically in the beginning of the tests. A similar but less pronounced behavior was also found for the CTed specimens at low sliding distances. At high sliding distances, no further decrease occurred. In contrast, an increase in wear rate was found for all types of coated specimens. These comparable low wear rates were found at the first- or/and the second-measurement points. After the initial rise of the wear rate, which ends at $\mathrm{S} \cdot \mathrm{N}$ value of around 2.5 (third checkpoint), the curve remained constant. The mean wear rate for all tests conducted and the results for the substrate hardness measurements are shown in Figure 7. The error bars illustrate the standard deviation of each test series. The black circles over the columns represent the substrate hardness of each batch. Since the dispersion of the hardness measurements was below $2 \%$ for all test series, the error bars do not appear. To compare the results more precisely, the wear and hardness values of all batches are listed in Table 3.

The values in Table 3 were organized according to the wear rate of each batch to make the analysis of the results easier. The highest wear resistance was found for the coated specimens. Hence, the first raw (AR specimens) showed the highest and the last raw (Comb-2 specimens) shows the lowest wear rate.

Table 3 further displays that the substrate hardness is not following the pattern of the wear rate. The highest wear rate was found for the hardest material. Furthermore, it was found that the DCT did not lead to a hardness increase. It rather resulted in a slight reduction of the hardness. A significant hardness reduction varying from $30 \%$ up to $36 \%$ was found for all coated specimens. As described in the methodology, these values represent the hardness of the substrate measured after the removal of the surface coating. 
TABLE 3: Wear and hardness results.

\begin{tabular}{lcccc}
\hline Test series & $\begin{array}{c}\text { Mean wear rate } \\
\left(10^{-13} \mathrm{~m}^{2} / \mathrm{N}\right)\end{array}$ & $\begin{array}{c}\text { Percentage of wear } \\
\text { rate reduction }\end{array}$ & $\begin{array}{c}\text { Hardness } \\
(\text { HV1 })\end{array}$ & $\begin{array}{c}\text { Percentage of } \\
\text { hardness reduction }\end{array}$ \\
\hline AR & 6.91 & - & 69.0 & - \\
CTed & 5.06 & 27 & 66.6 & 3 \\
Comb-1 & 4.79 & 31 & 44.9 & 35 \\
CrNC & 4.74 & 31 & 44.5 & 36 \\
Comb-2 & 3.71 & 46 & 48.1 & 30 \\
\hline
\end{tabular}

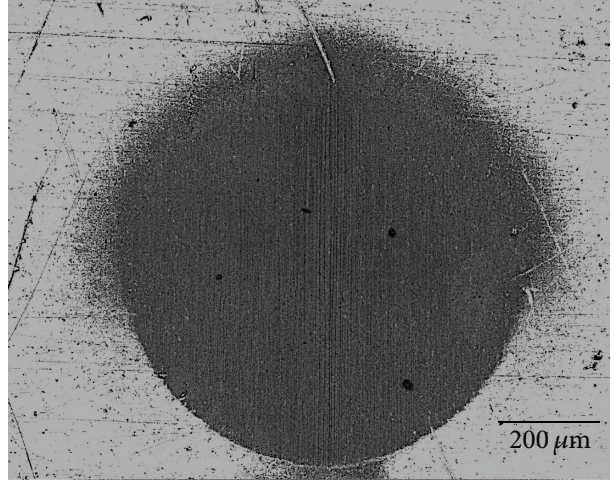

(a)

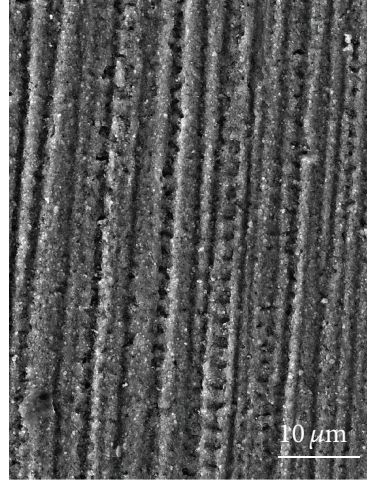

(b)

FIgURE 4: (a) Crater in an AR specimen with continuous grooves. (b) SEM image of the grooves in the crater (AR specimen). (b) is a zoom in the crater shown in (a).

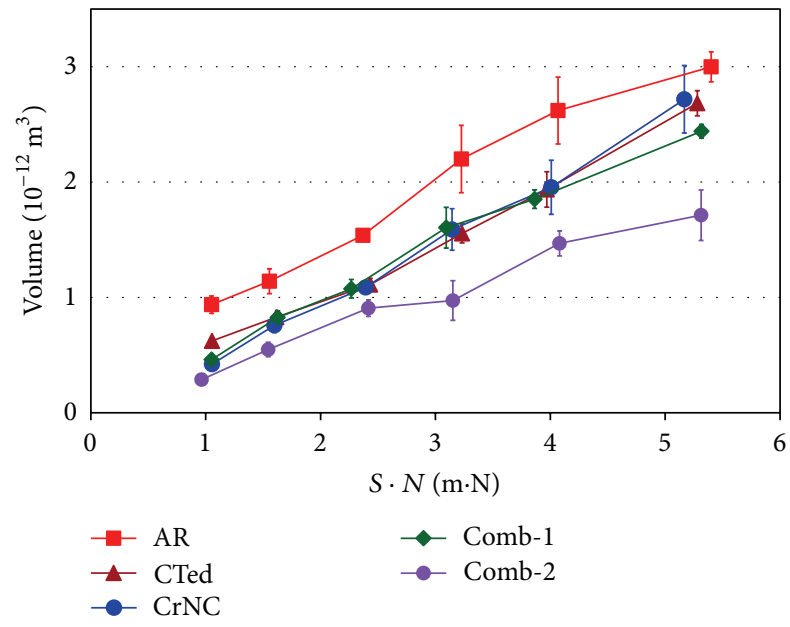

FIGURE 5: Wear volume versus sliding distance multiplied by the contact force.

4.2. X-Ray Diffraction. An X-Ray Diffraction analysis was carried out to investigate whether secondary phases or precipitates of the alloying elements could have been formed by the DCT. The occurrence of such phenomenon was mentioned by others [11-13] as the cause for an increase in wear resistance. Therefore, a comparative analysis between $\mathrm{AR}$ and CTed specimens was executed. The results of this analysis are shown in Figure 8.

In order to visualize both spectra in one diagram, the signal of the CTed specimens was numerically shifted (by

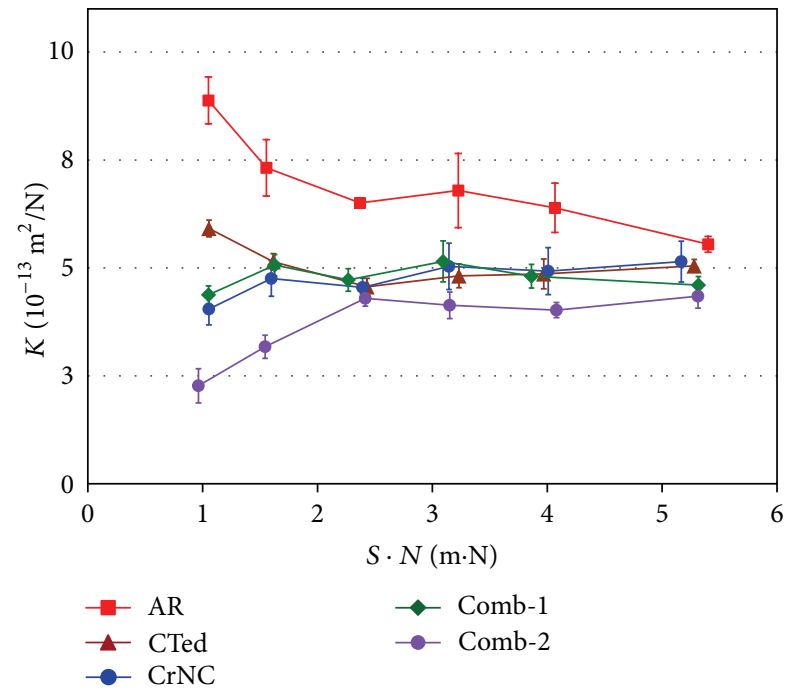

FIGURE 6: Wear rate versus sliding distance multiplied by the contact force.

the addition of a constant number to all values). While all distinct peaks occur in both spectra, the corresponding peak intensities differ significantly. The peak intensity can be correlated to the amount of each material or, more specifically, to the amount of the crystalline orientation of the material. The numbers over the peaks in the diagram represent the orientation of the aluminum crystals. Therefore, it needs to be mentioned that all identified peaks can be attributed to 


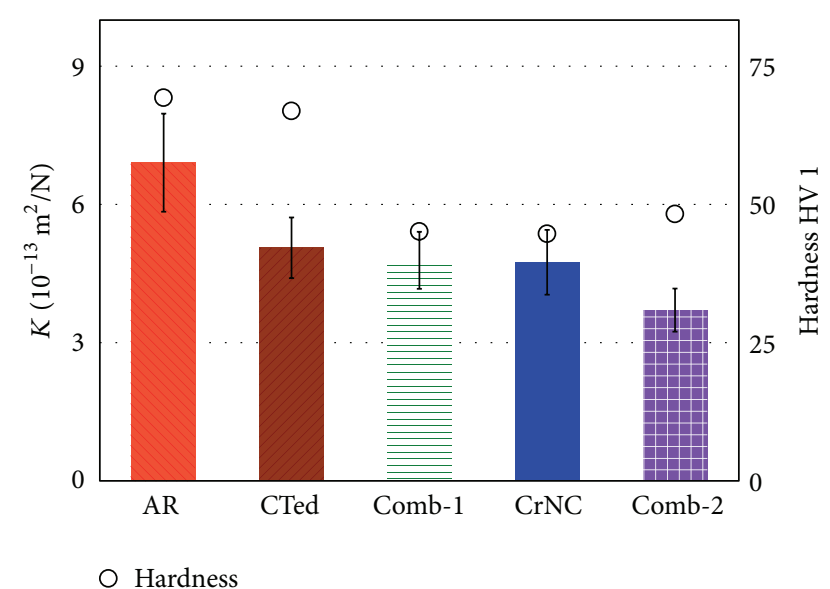

FIgURE 7: Wear rate and substrate hardness of all specimens types.

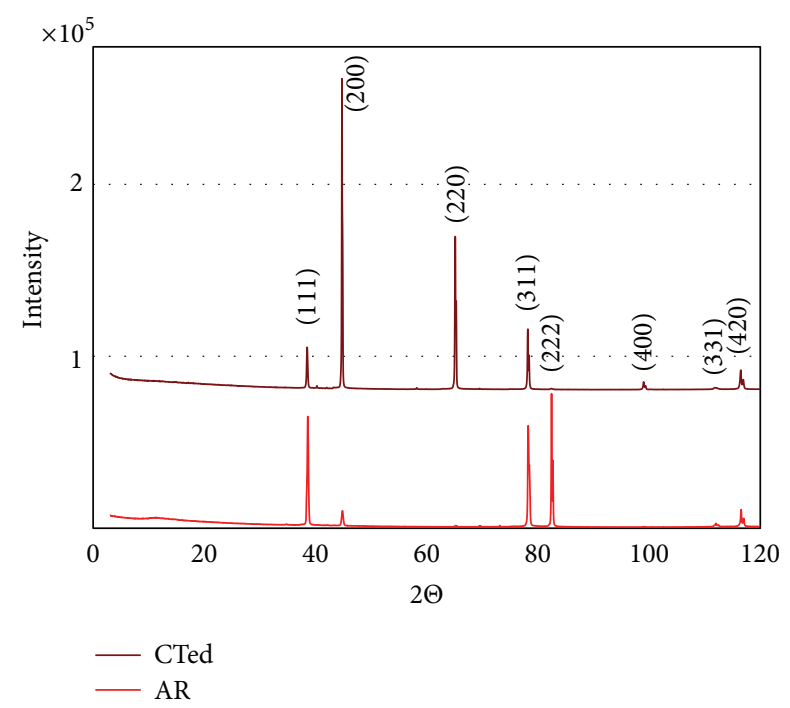

FIGURE 8: XRD spectrum of an AR and a CTed specimen.

aluminum. No secondary phases could be detected either in the CTed or in the AR specimens.

4.3. Microstructure. The microstructure investigation was carried out in order to try to find possible differences between the CTed and the AR specimens. The initial study included two basic metallographic methods: first, an analysis using optical microscopy of the polished surface (Figure 9) and second an analysis of the polished and etched surface (Figure 10). As the microstructure of the aluminum is influenced by the conformation process, it was ensured that the extracted samples had the same orientation. As a reference, the rolling direction of the primary aluminum block was taken. All shown microstructure images were taken from surface whose axial orientation can be described as longitudinal and lateral to the rolling direction.

In Figures 9(a) and 9(b), the polished surfaces of an AR and a CTed samples are shown. The bright surface indicates the aluminum structure. The dark marks are precipitates.
TABLE 4: Precipitations of the aluminum alloy.

\begin{tabular}{lccccc}
\hline Elements & $\mathrm{Al}(\%)$ & $\mathrm{Si}(\%)$ & $\mathrm{Mg}(\%)$ & $\mathrm{Fe}(\%)$ & $\mathrm{O} \mathrm{( \% )}$ \\
\hline $\mathrm{Al}_{x} \mathrm{Fe}_{x} \mathrm{Si}_{x}$ & 92.4 & 3.2 & 0.5 & 3.9 & - \\
$\mathrm{Mg}_{2} \mathrm{Si}$ & 90.8 & 4.6 & 4.3 & 0.3 & - \\
$\mathrm{SiO}_{2}$ & 73.3 & 7.9 & 0.1 & - & 18.7 \\
\hline
\end{tabular}

Two types of precipitates were found with this metallographic analysis. The gray rod-shaped marks are characteristic for $\mathrm{Mg}_{2} \mathrm{Si}$ and $\mathrm{Al}_{x} \mathrm{Fe}_{x} \mathrm{Si}_{x}$ precipitates. The smaller round shaped black precipitates are $\mathrm{SiO}_{2}$. Energy disperse analysis (EDS) executed with a SEM confirmed this analysis. The percentage of concentrations found for all elements are listed in Table 4. Similar particles were also found in other 6XXX aluminum alloys [24]. As the precipitations are very small, the EDX beam always incorporated the substrate around the precipitates. Therefore, aluminum is always present in all the measurements. The presence of $\mathrm{Mg}$ and of $\mathrm{Fe}$ in the $\mathrm{Al}_{x} \mathrm{Fe}_{x} \mathrm{Si}_{x}$ and the $\mathrm{Mg}_{2} \mathrm{Si}$ precipitates, respectively, is related to this same measurement procedure.

In Figure 10, the etched samples are shown. Similar to the unetched specimens, no distinctly higher or lower number of precipitates were found. The etched specimens further allow an evaluation of the grain size. Neither the orientation of the grains nor the grain size itself showed remarkable differences. Therefore, it can be mentioned that the DCT did not have any visually detectable effect with optical investigation methods.

4.4. Transmission Electron Microscope. To complete the microstructure study, a TEM analysis was carried out. Besides the big precipitates, detectable with the optical microscope, which have been identified via SEM/EDS, smaller precipitates with a size of approximately $50 \mathrm{~nm}$ and $4 \mathrm{~nm}$ were found using TEM (Figure 11(a)). The EDS/TEM analysis showed a concentration of copper in the bigger particles $\left(\mathrm{Cu}_{x} \mathrm{Al}_{x}\right.$ $50 \mathrm{~nm}$, Figures 11(b) and 11(c)). Copper precipitates have also been found by others $[25,26]$ in a 6 XXX aluminum alloy.

Furthermore, a large number of GP-zones $(4 \mathrm{~nm})$ were found arbitrarily distributed in the treated and the untreated specimens (Figures 12(a) and 12(b)).

Due to the very low size of the GP-zones, their chemical elements could not be distinctively identified. The EDX analysis revealed a random distribution of all alloying elements. The GP-zones were found in the AR and CTed specimens. A statement regarding the quantitative appearance of GP-zones could not be done once the distribution and the size of such zones were very disperse.

4.5. Differential Scanning Calorimetry (DSC). The graph in Figure 13 represents the difference of the DSC measurements between the CTed and the AR specimens. To obtain such a curve, two separate measurements were carried out. In both of them, an empty specimen container was taken as reference. Afterwards, the two curves were subtracted from each other to emphasize the differences between the modified and unmodified sample.

In order to clarify the nomenclature, the precipitation sequence for this type of aluminum alloy is presented. It is 


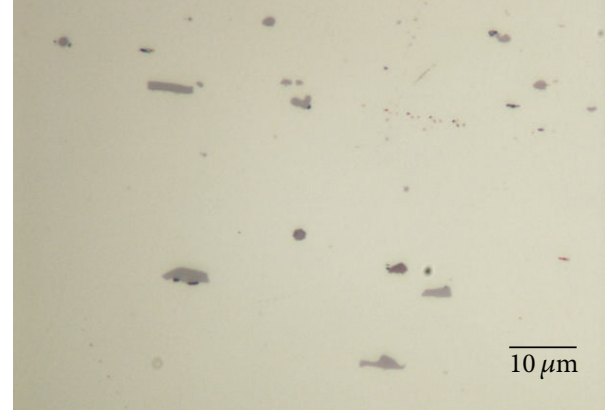

(a)

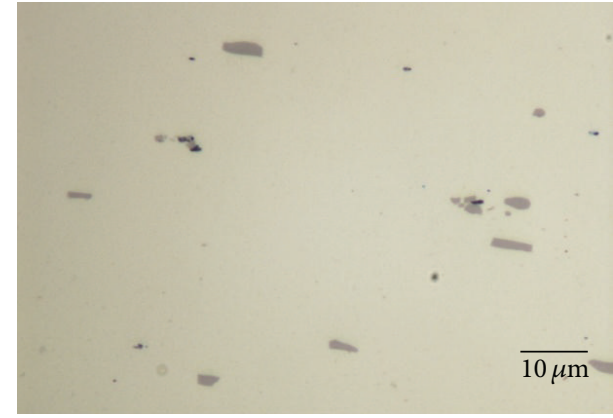

(b)

Figure 9: (a) Polished AR sample. (b) Polished CTed sample.

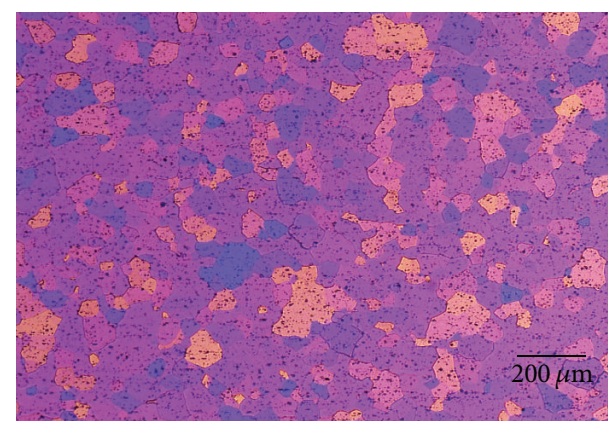

(a)

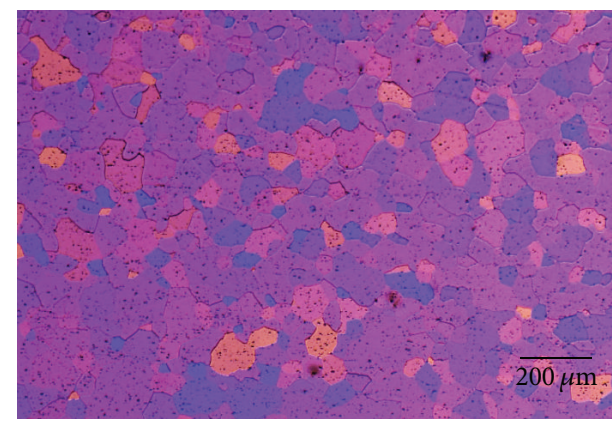

(b)

FIgure 10: (a) Etched, AR sample. (b) Etched, CTed sample.

generally agreed that the precipitation process in $\mathrm{Al}-\mathrm{Mg}-\mathrm{Si}$ alloys can be divided into the following steps [27]:

$$
\alpha(\mathrm{sss}) \longrightarrow \text { GP-zones } \longrightarrow \beta^{\prime \prime} \longrightarrow \beta^{\prime} \longrightarrow \beta,
$$

where $\alpha($ sss $) \rightarrow$ is the supersaturated solid solution. GPzones occur in form of irregular structures (Figure 12). $\beta^{\prime \prime}$ precipitates are usually needle-shaped and occur along $\langle 100\rangle_{\mathrm{Al}}$ plane, with a monoclinic structure. $\beta^{\prime}$ precipitates are rod-shaped and occur in the same plane. $\beta$ phase $\left(\mathrm{Mg}_{2} \mathrm{Si}\right)$ is usually formed as platelets along $\{100\}$ plane of aluminum.

A wide endothermic peak $\left(80^{\circ} \mathrm{C}-160^{\circ} \mathrm{C}\right)$ with the center at $115^{\circ} \mathrm{C}$ can be observed in Figure 13. This peak can be related to dissolution of GP-zones [28]. At higher temperatures, two exothermic peaks were revealed at approximately $235^{\circ} \mathrm{C}$ and $310^{\circ} \mathrm{C}$. The peak centered at $235^{\circ} \mathrm{C}$ indicates the formation of $\beta^{\prime \prime}$ and the one at $310^{\circ} \mathrm{C}$ is a sign for $\beta^{\prime}$ precipitations $[28,29]$. The endothermic ramp above $325^{\circ} \mathrm{C}$ is attributed to the start of a dissolution process for just formed precipitates.

\section{Discussion}

5.1. X-Ray Diffraction. The first method used to determine the formation of precipitates was XRD. The spectra depicted that the crystal orientations of the scanned specimens were different. It is unclear if the different orientations were caused by the cryogenic treatment or if they are related to the fact that two different specimens were examined. In this case, the difference in crystal orientation is related to inhomogeneity of the material.

However, no other elements nor second phases were found in the CTed or in the AR specimens. Although this result may seem surprising, as the substrate contains alloying elements, the reason for that is associated with the detection limit of the equipment (between $0.5 \%$ and $3 \%$ ). Small particles may hence be hindering their detection using XRD. As shown in Table 1, the maximum alloy element concentration is specified with $0.5 \%$.

5.2. Microstructure. No significant differences between the CTed and the AR specimens were found. Difficulties associated with this microstructural analysis method are the small sizes of the sections investigated. As the distribution of precipitates is not homogeneous, differences can be easily found (or not) depending on the section that was photographed. Therefore, often-found assumption that $\mathrm{Mg}_{2} \mathrm{Si}, \mathrm{Al}_{x} \mathrm{Fe}_{x} \mathrm{Si}_{x}$, or similar precipitates are generated by DCTs could not be confirmed. It is further unlikely that such big precipitates are directly generated by the DCT, as precipitates are usually formed by diffusion. The low temperatures during the DCT do not favor their formation.

The TEM/EDS analysis showed an appearance of smaller precipitates (size of $50 \mathrm{~nm}$ ) with a high concentration of cupper. This led to the assumption that such precipitates consisted of metastable $\mathrm{Cu}_{2} \mathrm{Al}$ [29]. Furthermore, small GPzones were found with the TEM. 


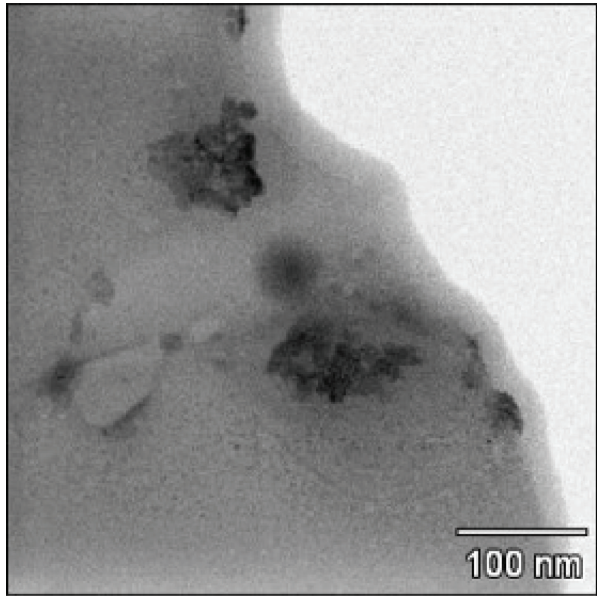

(a)

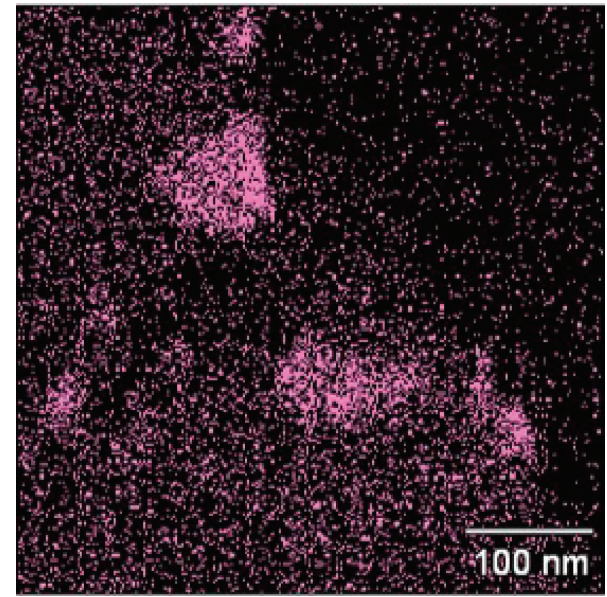

(b)

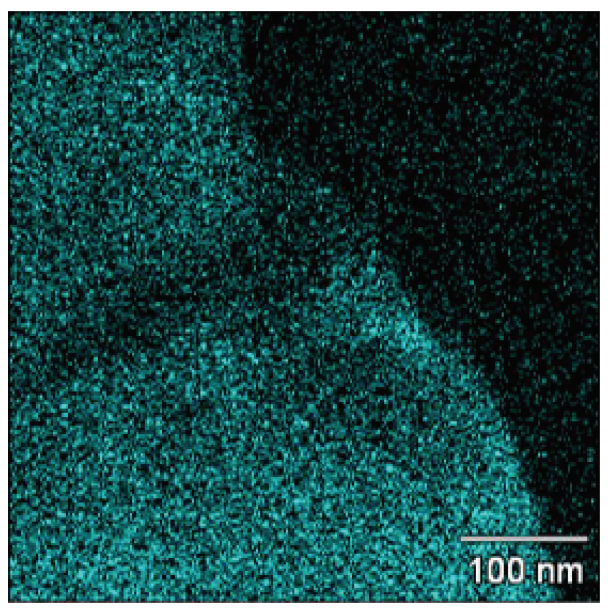

(c)

FIgURE 11: (a) Bright field TEM image of an AR sample (the small dark dots represent GP-zones). (b) Element analysis of the GP-zones (pink dots indicate the appearance of $\mathrm{Cu}$ ). (c) Element analysis of the GP-zones (green dots indicate the appearance of Al).

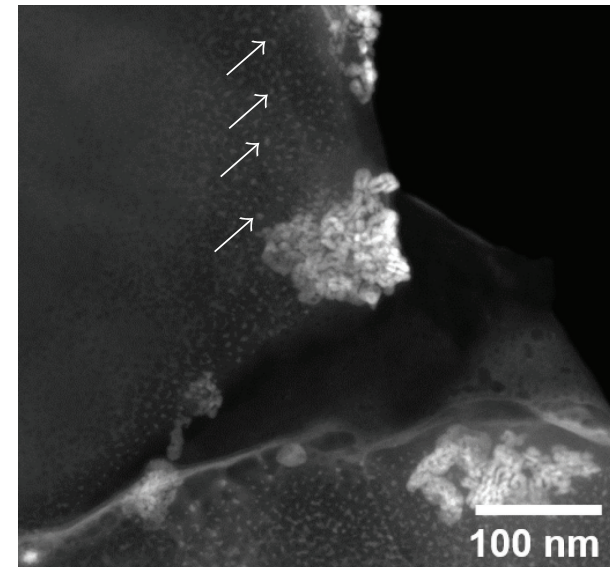

(a)

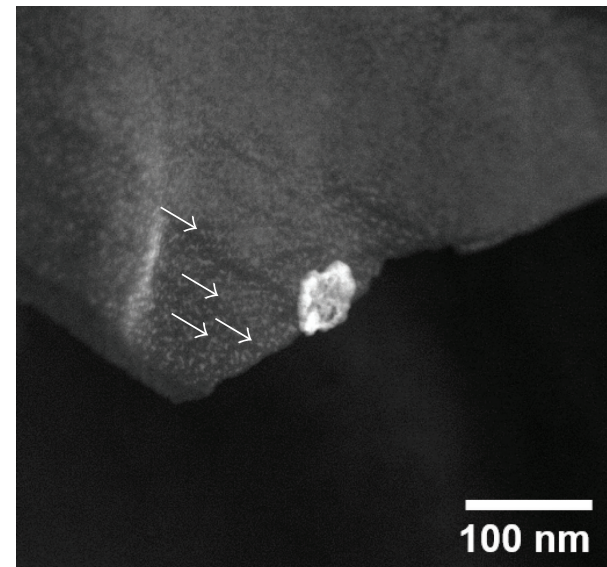

(b)

FIGURE 12: (a) Dark field TEM image of an AR sample (small, widely distributed white dots in the size of approximately $4 \mathrm{~nm}$ are GP-zones). (b) Dark field TEM image of a DCT sample (small, widely distributed white dots in the size of approximately $4 \mathrm{~nm}$ are GP-zones). 


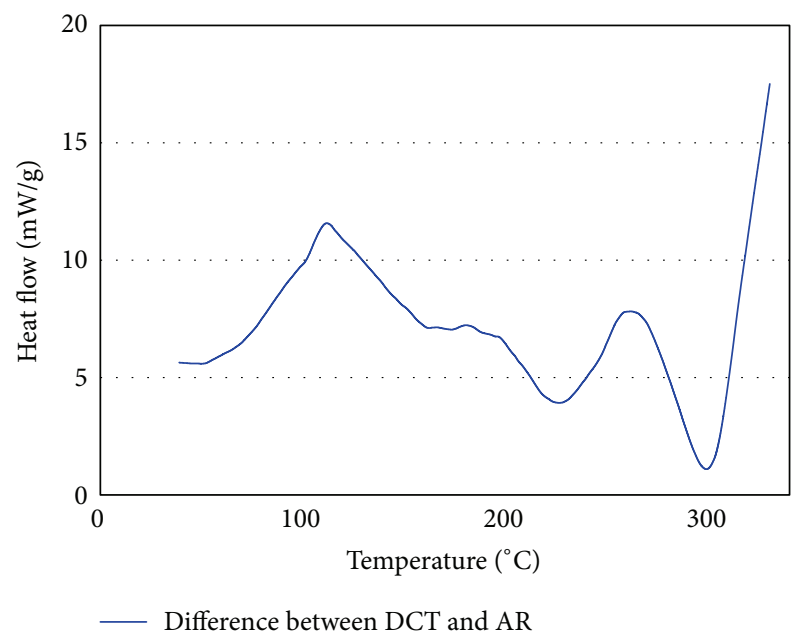

Figure 13: Differential scanning calorimetry (signal of the CTed sample with the AR material as reference).

The decreasing solubility of the alloying elements at lower temperatures is likely to be responsible for the generation of the GP-zones. At low temperatures, the movement of the atoms, as well as the distance between them, is decreasing. Therefore, it is energetically more favorable to emit chemical impurities from the solid aluminum solution, because the difference in the atomic radius disturbs the crystalline structure. This can lead to the emission of alloying elements, which accumulate in nanosized GP-zones. Whether the contraction of the aluminum structure is strong enough to emit alloying elements depends on the discrepancy between the atomic radii of the aluminum atoms and the alloying elements.

As shown with the comparative images in Figure 12, the small sections scanned with the TEM do not allow a serious proof that the DCT increases the number of GPzones. Anyhow, GP-zones as well as the small precipitates (size $50 \mathrm{~nm}$ ) were found in the AR and as well in the CTed specimens. Their occurrence in both types of specimens is not surprising, as the natural aging process also generates GP-zones [29]. A robust and conclusive screening of the microstructure with the TEM would be too cost- and timeconsuming. For this reason, another analysis method, which includes a larger volume fraction, was used to confirm the generation of GP-zones by DCTs.

5.3. Differential Scanning Calorimetry. As explained above, the curve presented in Figure 13 shows the difference between the AR and the CTed specimens. The found peaks reveal a clear difference generated by the DCT. The curve depicted a wide endothermic peak between $80^{\circ} \mathrm{C}$ and $160^{\circ} \mathrm{C}$, which can be associated with the dissolution of GP-zones. The applied temperature regime of the DSC analysis dissolved GP-zones that have been generated by the DCT. The volume under the peak indicates that the number of dissolved GP-zones is extensive. Therefore, an improved wear resistance due to the generation of GP-zones seems reasonable. The peak-width indicates that the size and presumably the components of the GP-zones are different, which confirms the assumption that the GP-zones cannot be related to only one type of alloying element.

The results illustrated in Figure 13 also showed two exothermic peaks $\left(235^{\circ} \mathrm{C}\right.$ and $\left.310^{\circ} \mathrm{C}\right)$, attributed to the generation of $\beta^{\prime \prime}$ and $\beta^{\prime}$ precipitates. These peaks indicate an increased amount of precipitate generation in the CTed specimens. As explained before, it is unlikely that DCTs are generating big precipitates. The diffusion-controlled accumulation of alloying elements is not likely to appear at such low temperatures. It is more probable that the just ended dissolution process of the GP-zones (in between $80^{\circ} \mathrm{C}$ and $160^{\circ} \mathrm{C}$ ) supported the generation of bigger precipitates. Other authors mentioned the possibility that larger GP-zones might not be dissolved completely due to fast heating rate of $20 \mathrm{~K} / \mathrm{min}$. Considering this, not completely dissolved GPzones can act as nuclei for the precipitates and accelerate their formation $[28,29]$.

5.4. Hardness. To improve the understanding of the hardness results, it is again mentioned that the hardness of the substrates was measured and compared. The surface coating was smoothly removed (by polishing) before the hardness tests were carried out. This procedure was carried out to measure the hardness of the substrate and thereby uncover changes in the microstructure of the substrate.

As shown in Figure 7, the hardness measurements revealed a significant effect of the coating process on the hardness of the substrate. All coated specimens showed a significant decrease in the hardness. Therefore, the discussion of the coated and uncoated specimens is done separately.

5.4.1. Uncoated Specimens. The hardness of the CTed specimens showed a hardness reduction of $3 \%$ compared to the AR specimens. This result was not expected, since the CTed specimens contain a significantly higher number of GPzones. The results of other researchers might explain these conflicting results. It was found that DCTs reduced residual stresses in aluminum alloys [6,30]. An effect of residual stresses on the hardness of materials is widely known and was already proven for similar aluminum alloys [31, 32]. Taking into account that the reduction of residual stresses decreases the hardness and that the generation of GP-zones increases the hardness, the sum of both effects can be either an increase or a decrease in the hardness of the aluminum alloy.

5.4.2. Coated Specimens. The batches CrNC, Comb-1, and Comb-2 were coated with $\mathrm{CrN}$. One reason for the selection of the CrN coating was its comparably low deposition temperature. As evidenced by these results, the temperature of the deposition process, even though lower than for other coatings, affected the microstructure of the alloy. The exact temperature during the coating process was not provided by the coating company. The surface temperature was estimated to be between $100^{\circ} \mathrm{C}$ and $150^{\circ} \mathrm{C}$.

As explained in Section 5.3, a wide endothermic peak, which indicated that the GP-zones were dissolved, appeared between $80^{\circ} \mathrm{C}$ and $160^{\circ} \mathrm{C}$ during the DSC measurements. Assuming the deposition time and the temperature during the coating process, a dissolution of GP-zones and small 
precipitates in the near surface area is highly possible. Such behavior was found by other researchers [29], who applied a preaging process (at $100^{\circ} \mathrm{C}$ ), that also led to dissolved GPzones and a reduced hardness. The fact that the measured hardness is only slightly higher than the hardness of pure aluminum supports this assumption [33].

Considering this in the actual discussion, all coated batches were unintentionally heat-treated during the coating process, for which reason their hardness is comparably low. The hardness of the batches Comb- 1 and CrNC is nearly equal. The hardness of the Comb-2 batch increased $6 \%$, compared with its coated partners. This increase can be contributed to the increased number of GP-Zones, generated by the subsequently executed DCT.

5.5. Wear Results. As shown in Figure 5, the AR specimens had the highest wear rate for all sliding distances. Especially at a low sliding distances (the first-two checkpoints), the wear rates are markedly high. The same behavior was found for the CTed specimens. Some percentage of this initial high wear rate can be associated with an overestimation of the removed volume at low sliding distances. It occurs due to the difficulty in measuring the diameter of the crater [22]. Therefore, a slight overestimation can be considered for the first points. Notice that all uncoated specimens showed a pronounced scuffed area around the crater (Figure 2). This turned the measurement of its diameter and consequently the determination of the volume loss and of the wear rate into a less precise task. Other authors found similar behavior especially for uncoated soft materials [20]. In the case of a coated surface, the scuffed area around the crater was much smaller and this type of measurement inaccuracy could be neglected.

In contrast, a low wear rate was found for the firstmeasurement points of all coated specimens. It is easy to perceive that this effect is generated by the wear resistant coating. Subsequent tests carried out to detect the sliding distance necessary to perforate the surface coating indicated a breakthrough after a sliding distance of $0.3 \mathrm{~m}$. Therefore, the first-measurement point represents a mixture of the surface coating and the substrate material and does not represent the wear rate of the pure coating. As the coating is only present on the surface, the biggest wear resistance can hence be expected for low sliding distances. After the perforation of the coating, the volume ratio between coating and substrate is continuously decreasing. Hence, the wear resistance slightly decreased with an increase in sliding distance. This effect can be seen in Figure 6. In general, the wear rate reduction is relatively high considering that the height of the deposited coating was only $660 \mathrm{~nm}$ (Figure 3 ).

The CTed specimens led to a similar reduction in wear rate as the one observed for the CrNC specimens. As shown by the DSC tests, additional GP-zones were generated due to the DCT. Such zones are responsible for the improved wear resistance. As widely known, GP-zones and precipitates exhibit a higher wear resistance than the pure aluminum. As reported in Table 1, several alloying elements are present in the aluminum alloy, for which reason it is expected that the GP-zones consisted of diverse alloying elements.
In order to generate an aluminum alloy with superior wear resistance, one batch of specimens was first modified cryogenically and afterwards coated with CrN (batch Comb1). Since the DCT changes the microstructure in the entire material and the $\mathrm{CrN}$ mainly acts in near surface regions, a superposition of both effects was expected for the specimens treated with both modification methods. However, such superposition did not occur for the Comb-1 batch. As explained before, the coating process had a side effect on the substrate material, which dissolved GP-zones and small precipitates. It therefore also affected the wear resistance. For this reason, the results of the Comb-1 specimens were similar to the CrNC specimens.

To confirm that a superposition of both effects is possible, an additional test series was carried out. The Comb-2 batch was first coated with CrN and afterwards DCT. During the coating process, the GP-zones were dissolved in the same way. However, the subsequent DCT generated new GP-zones and therefore reversed the effects of the coating process. Using this modification sequence, the combination of an increased number of GP-zones with a surface coating generated a significant improvement (of 48\%) in wear resistance (Figure 7).

\section{Conclusion}

The results of the wear tests showed that DCT led to an improved wear resistance of the aluminum alloy. CrN surface coating showed a likewise improvement of the wear behavior. If both modification methods are executed in the correct order (first CrN coating and second DCT), a superposition of such effects can be reached. A reversed order does not lead to similar effects, since the temperature rise, which occurs during the coating process, eliminates the microstructural changes and dissolves the GP-zones.

The microstructural analyses revealed that DCT did not generate large precipitates or other significant microstructural changes like in the grain size. Such effects are diffusion controlled and therefore require higher temperatures. However, a distinct generation of small and widely dispersed GPzones was detected with DSC. The results showed a clearly pronounced dissolution of GP-zones for the cryogenically treated specimens. The authors claim that the formation of GP-zones generated during the DCT was the main reason for the improved wear resistance.

\section{Competing Interests}

The authors declare that there are no competing interests regarding the publication of this paper.

\section{Acknowledgments}

The authors would like to acknowledge the Brazilian program Science Without Borders from CNPq for the financial support of the project (401671/2013-5 and 314034/2013-7). They also would like to thank Kyros Tecnologia Ltda. for carrying out deep cryogenic treatments and the Department of Materials Engineering in the Pontifícia Universidade 
Católica do Rio de Janeiro (PUC-Rio) for conducting TEM measurements.

\section{References}

[1] R. J. Arsenault, "The strengthening of aluminum alloy 6061 by fiber and platelet silicon carbide," Materials Science and Engineering, vol. 64, no. 2, pp. 171-181, 1984.

[2] S. Seifeddine, S. Johansson, and I. L. Svensson, "The influence of cooling rate and manganese content on the $\beta$-Al5FeSi phase formation and mechanical properties of Al-Si-based alloys," Materials Science and Engineering A, vol. 490, no. 1-2, pp. 385390, 2008.

[3] H. Torabian, J. P. Pathak, and S. N. Tiwari, "Wear characteristics of Al-Si alloys," Wear, vol. 172, no. 1, pp. 49-58, 1994.

[4] B. Podgornik, F. Majdic, V. Leskovsek, and J. Vizintin, "Improving tribological properties of tool steels through combination of deep-cryogenic treatment and plasma nitriding," Wear, vol. 288, pp. 88-93, 2012.

[5] D. Mohan Lal, S. Renganarayanan, and A. Kalanidhi, "Cryogenic treatment to augment wear resistance of tool and die steels," Cryogenics, vol. 41, no. 3, pp. 149-155, 2001.

[6] P. Chen, L. Malone, R. Bond, and P. Torres, "Effects of cryogenic treatment on the residual stress and mechanical properties of an aerospace aluminum alloy (NASA)," 2000.

[7] K. E. Lulay, K. Khan, and D. Chaaya, "The effect of cryogenic treatments on 7075 aluminum alloy," Journal of Materials Engineering and Performance, vol. 11, no. 5, pp. 479-480, 2002.

[8] X.-Q. Jiang, N. Li, H. He, X.-J. Zhang, C.-C. Li, and H. Yang, "Effect of cryogenic treatment on mechanical properties and microstructures of 3102 Al-alloy," Materials Science Forum, vol. 546-549, no. 2, pp. 845-848, 2007.

[9] W. D. Zhang, J. Y. Yang, J. Z. Dang, Y. Liu, and H. Xu, "Effects of cryogenic treatment on mechanical properties and corrosion resistance of LC4 aluminum alloy," Advanced Materials Research, vol. 627, pp. 694-697, 2013.

[10] J. Wang, X. Xue, Z. Yang, H. Zhang, and Y. Zhou, "Effect of cryogenic treatments on mechanical properties of 2A11 aluminum alloy," Advanced Materials Research, vol. 146-147, pp. 1646-1650, 2011.

[11] S. Zhirada, Effect of cryogenic treatment on the mechanical properties of steel and aluminum alloys [M.S. of Applied Science], Mechanical and Industrial Engineering, Library and Archives Canada, Concordia University, Montreal, Canada, 2005.

[12] G. Li, H. Wang, Y. Cai, and X. Yuan, "Behavior of $\beta\left(\mathrm{Mg}_{17} \mathrm{Al}_{12}\right)$ phases in mg-al alloy subject to cycling cryogenic treatment," Key Engineering Materials, vol. 575-576, pp. 390-393, 2014.

[13] S. Karabay, M. Yilmaz, and M. Zeren, "Investigation of extrusion ratio effect on mechanical behaviour of extruded alloy AA6101 from the billets homogenised-rapid quenched and as-cast conditions," Journal of Materials Processing Technology, vol. 160, no. 2, pp. 138-147, 2005.

[14] K. Gu, J. Wang, and Y. Zhou, "Effect of cryogenic treatment on wear resistance of Ti-6Al-4V alloy for biomedical applications," Journal of the Mechanical Behavior of Biomedical Materials, vol. 30, pp. 131-139, 2014.

[15] G. Y. Liang, T. T. Wong, J. M. K. MacAlpine, and J. Y. Su, “A study of wear resistance of plasma-sprayed and laser-remelted coatings on aluminium alloy," Surface and Coatings Technology, vol. 127, no. 2-3, pp. 233-238, 2000.

[16] I. P. Mertsalo, V. T. Yavors'kyi, M. D. Klapkiv, and R. S. Mardarevych, "Wear resistance of anodic-spark coatings on aluminum alloys," Materials Science, vol. 39, no. 1, pp. 136-139, 2003.

[17] S. Guanhong, H. Xiaodong, J. Jiuxing, and S. Yue, "Parametric study of $\mathrm{Al}$ and $\mathrm{Al}_{2} \mathrm{O}_{3}$ ceramic coatings deposited by air plasma spray onto polymer substrate," Applied Surface Science, vol. 257, no. 17, pp. 7864-7870, 2011.

[18] F. Zhou, C.-M. Suh, S.-S. Kim, and R.-I. Murakami, “Tribological behavior of $\mathrm{CrN}$ coating on aluminum alloys deposited by arc ion plating," Journal of Materials Research, vol. 17, no. 12, pp. 3133-3138, 2002.

[19] F. Zhou, C.-M. Suh, S.-S. Kim, and R.-I. Murakami, "Slidingwear behavior of TIN- and CrN-coated 2024 aluminum alloy against an $\mathrm{Al}_{2} \mathrm{O}_{3}$ ball," Tribology Letters, vol. 13, no. 3, pp. 173178, 2002.

[20] R. I. Trezona and I. M. Hutchings, "Three-body abrasive wear testing of soft materials," Wear, vol. 233-235, pp. 209-221, 1999.

[21] K. Adachi and I. M. Hutchings, "Wear-mode mapping for th micro-scale abrasion test," Wear, vol. 255, no. 1-6, pp. 23-29, 2003.

[22] M. G. Gee, A. J. Gant, I. M. Hutchings et al., "Results from an interlaboratory exercise to validate the micro-scale abrasion test," Wear, vol. 259, no. 1-6, pp. 27-35, 2005.

[23] K.-H. Z. Gahr, "Wear by hard particles," Tribology International, vol. 31, no. 10, pp. 587-596, 1998.

[24] W. Q. Song, P. Krauklis, A. P. Mouritz, and S. Bandyopadhyay, "The effect of thermal ageing on the abrasive wear behaviour of age-hardening $2014 \mathrm{Al} / \mathrm{SiC}$ and $6061 \mathrm{Al} / \mathrm{SiC}$ composites," Wear, vol. 185, no. 1-2, pp. 125-130, 1995.

[25] J. Ouyang, E. Yarrapareddy, and R. Kovacevic, "Microstructural evolution in the friction stir welded 6061 aluminum alloy (T6temper condition) to copper," Journal of Materials Processing Technology, vol. 172, no. 1, pp. 110-122, 2006.

[26] H. Kaçar, E. Atik, and C. Meriç, "The effect of precipitationhardening conditions on wear behaviours at 2024 aluminium wrought alloy," Journal of Materials Processing Technology, vol. 142, no. 3, pp. 762-766, 2003.

[27] G. B. Burger, A. K. Gupta, P. W. Jeffrey, and D. J. Lloyd, "Microstructural control of aluminum sheet used in automotive applications," Materials Characterization, vol. 35, no. 1, pp. 2339, 1995.

[28] W. F. Miao and D. E. Laughlin, "Differential scanning calorimetry study of aluminum alloy 6111 with different pre-aging treatments," Journal of Materials Science Letters, vol. 19, no. 3, pp. 201-203, 2000.

[29] W. F. Miao and D. E. Laughlin, "Effects of $\mathrm{Cu}$ content and preaging on precipitation characteristics in aluminum alloy 6022," Metallurgical and Materials Transactions A: Physical Metallurgy and Materials Science, vol. 31, no. 2, pp. 361-371, 2000.

[30] Q.-C. Wang, L.-T. Wang, and W. Peng, “Thermal stress relief in 7050 aluminum forgings by uphill quenching," Materials Science Forum, vol. 490-491, pp. 97-101, 2005.

[31] G. P. Dolan and J. S. Robinson, "Residual stress reduction in 7175-T73, 6061-T6 and 2017A-T4 aluminium alloys using 
quench factor analysis," Journal of Materials Processing Technology, vol. 153-154, no. 1-3, pp. 346-351, 2004.

[32] W. R. LaFontaine, C. A. Paszkiet, M. A. Korhonen, and C.-Y. Li, "Residual stress measurements of thin aluminum metallizations by continuous indentation and x-ray stress measurement techniques," Journal of Materials Research, vol. 6, no. 10, pp. 20842090, 1991.

[33] Y. Ito and Z. Horita, "Microstructural evolution in pure aluminum processed by high-pressure torsion," Materials Science and Engineering A, vol. 503, no. 1-2, pp. 32-36, 2009. 

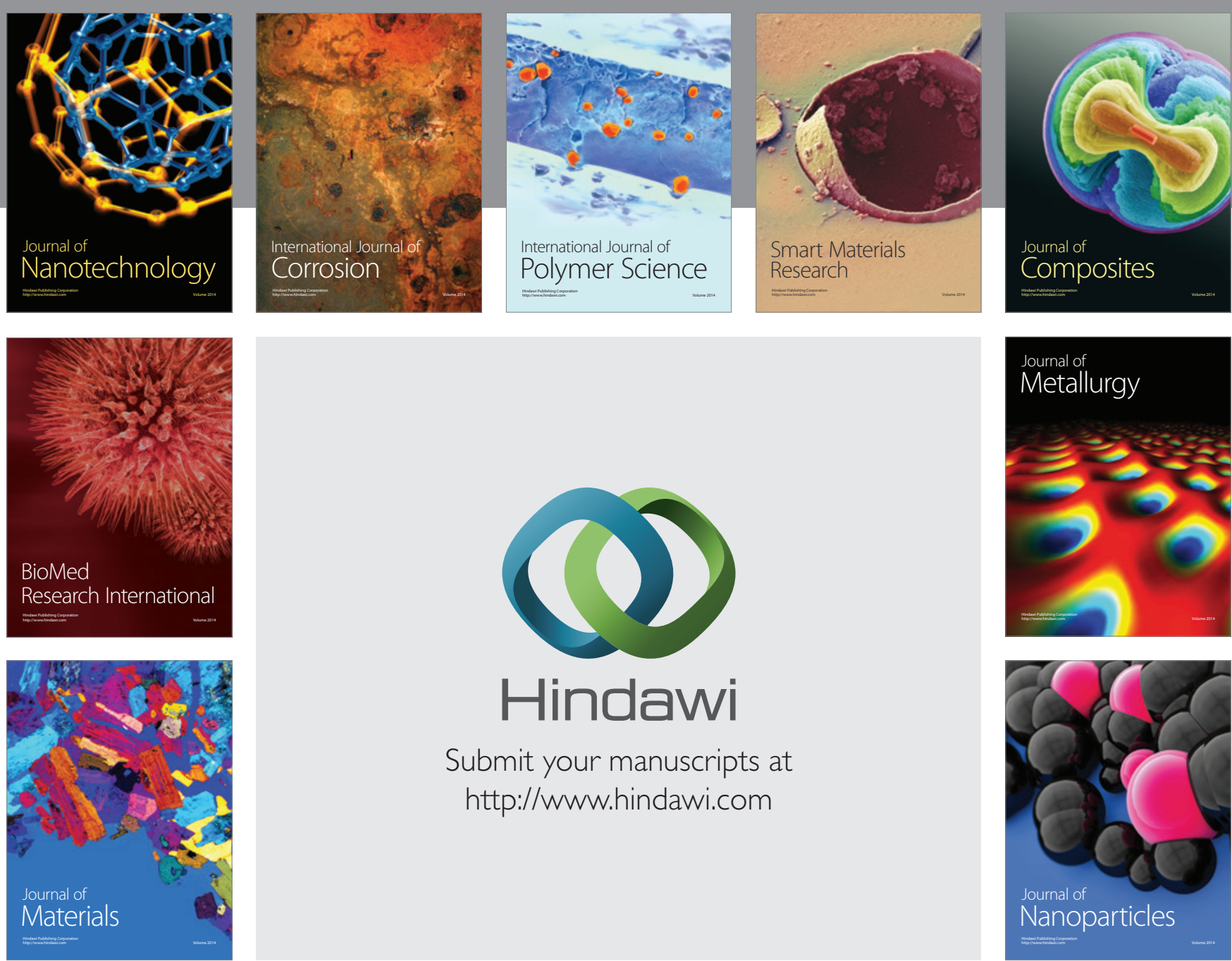

\section{Hindawi}

Submit your manuscripts at

http://www.hindawi.com

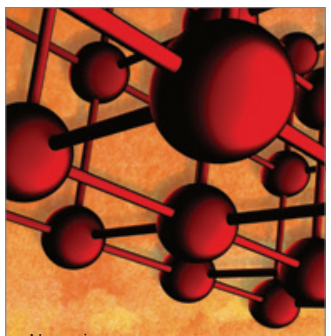

Materials Science and Engineering
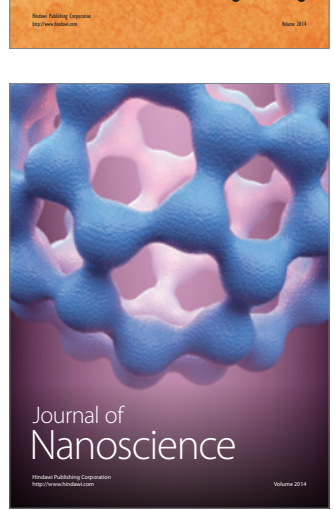
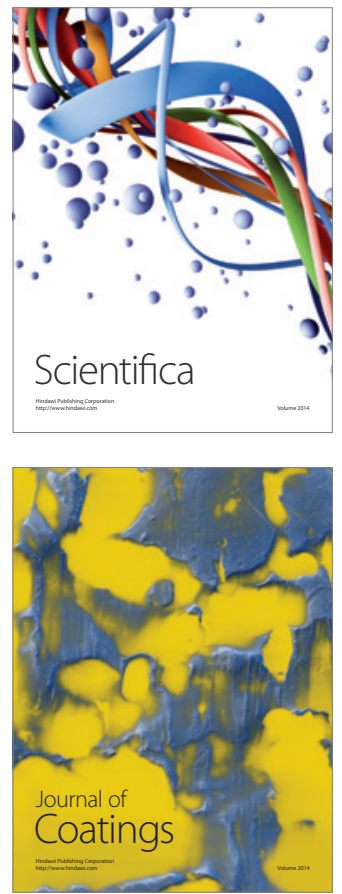
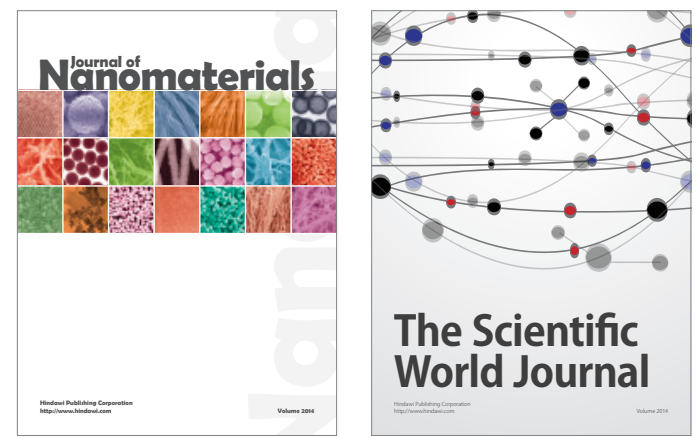

The Scientific World Journal
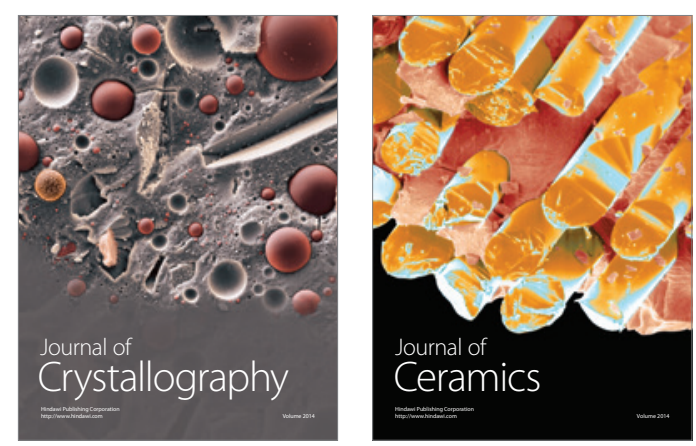
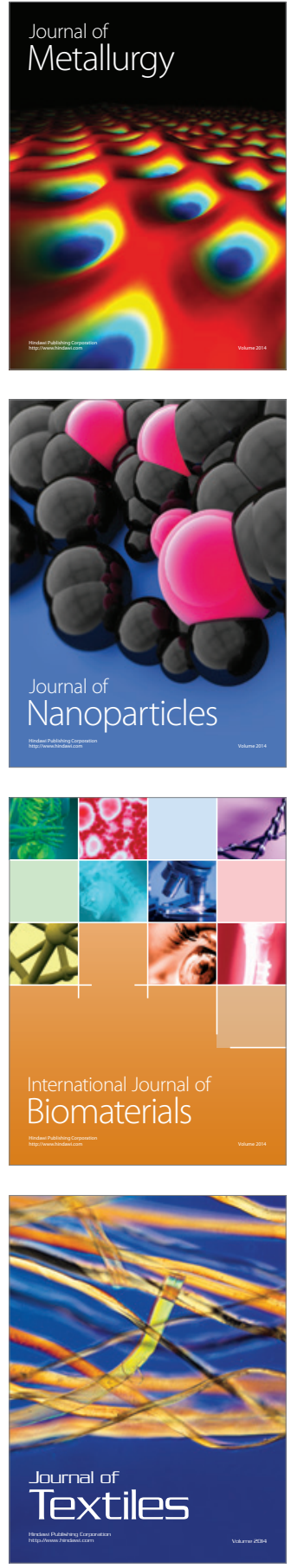